\title{
As Mulheres Sexualizadas pelo Poder Econômico
}

\author{
Las Mujeres Sexualizadas por el Poder Económico \\ Women Sexualized by the economic power
}

\author{
Paulo José Angelo Andrade ${ }^{1}$ \\ Michelle Martins Papini Mota ${ }^{2}$
}

\begin{abstract}
Resumo
As questões de gênero, sexo, identidade de gênero e autoria feminina estão em evidência na pós-modernidade. A doutrina criminológica hoje, em um mundo culturalmente globalizado, contribui para o fortalecimento de estereótipos os quais, quando conjugados com o poder econômico, influenciam as relações sociais, em especifico a modernidade-colonialidade. A Criminologia estabeleceu dentre ideias e padrões, alguns específicos e esperados das mulheres. Isto criou os paradigmas positivos e negativos hoje vigentes. Esse é um dos motivos que fazem as mulheres que desejam exercer sua sexualidade dentro de suas convicções serem tidas, às vezes, como infratoras e não merecedoras de um tratamento igualitário às demais. Ao passo que a sociedade tolera e usufrui quando se trata das benesses econômicas. Para tanto, analisaremos dois casos como paradigmas, para apresentarmos o estudo acerca da coisificação da mulher por si ou pelo próprio Poder Econômico, considerando sua subalternidade, desde o colonialismo de gênero até o decolonialismo.
\end{abstract}

Palavras-chave: Mulher; Criminologia; Sexualidade; Poder Econômico; Decolonialidade.

\section{Resumen}

As questões de gênero, sexo, identidade de gênero e autoria feminina estão em evidência na pós-modernidade. A doutrina criminológica hoje, em um mundo culturalmente globalizado, contribui para o fortalecimento de estereótipos os quais, quando conjugados com o poder econômico, influenciam as relações sociais, em especifico a modernidade-colonialidade. A Criminologia estabeleceu dentre ideias e padrões, alguns específicos e esperados das mulheres. Isto criou os paradigmas positivos e negativos hoje vigentes. Esse é um dos motivos que fazem as mulheres que desejam exercer sua sexualidade dentro de suas convicções serem tidas, às vezes, como infratoras e não merecedoras de um tratamento igualitário às demais. Ao passo que a sociedade tolera e usufrui quando se trata das benesses economicas. Para tanto, analisaremos dois casos como paradigmas, para apresentarmos o estudo acerca da coisificação da mulher por si ou pelo próprio Poder Econômico, considerando sua subalternidade, desde o colonialismo de gênero até o decolonialismo.

Palavras-chave: Mulher; Criminologia; Sexualidade; Poder Econômico; Decolonialidade

\begin{abstract}
The questions of gender, sex, gender identity and female authorship are evident in postmodernity. Criminological doctrine today, in a culturally globalized world, contributes to the strengthening of stereotypes which, when
\end{abstract}

\footnotetext{
${ }^{1}$ Mestre, Bacharel em Direito, professor, Belo Horizonte, Minas Gerais, Brasil, paulojaandrade@gmail.com. Trabalho apresentado no I Seminário Latino-Americano de Estudos em Cultura -SEMLACult, Foz do Iguaçu/PR, Brasil, 2017.

${ }^{2}$ Especialista, Bacharel em Direito, Belo Horizonte, Minas Gerais, Brasil, michellepapini@ hotmail.com Trabalho apresentado no I Seminário Latino-Americano de Estudos em Cultura -SEMLACult, Foz do Iguaçu/PR, Brasil, 2017.
} 
coupled with economic power, influence social relations, in particular, modernity-coloniality. Criminology established among ideas and patterns, some specific and expected of women. This created the current positive and negative paradigms. This is one of the reasons why women who wish to exercise their sexuality within their convictions are sometimes seen as infringing and not deserving of equal treatment to others. Whereas society tolerates and enjoys when it comes to economic benefits. In order to do so, we will analyze two cases as paradigms, to present the study about women's self-classification or by the economic power itself, considering its subalternity, from gender colonialism to decolonialism.

Keywords: Woman; Criminology; Sexuality; Economic Power; Decoloniality.

\section{Introdução}

O presente trabalho é decorrente da análise da atual situação de coisificação de mulheres frente a realidade socioeconômica. Esta realidade frequentemente é imputada à sociedade machista. A perspectiva é pacífica e inconteste, todavia, cabe virar o olhar da própria coisificação da mulher visando galgar ganhos econômicos, sociais e profissionais.

O objetivo do presente estudo é analisar a situação da mulher face à função da criminologia, não limitada ao estudo e tratamento criminoso, mas à análise das diferenças sociais, de gênero e de submissão ao Poder Econômico, tendo em foco o decolonialismo e a subalternidade.

Interessante as críticas de María Lugones à Anibal Quijano com relação à análise da colonialidade e gênero:

O conceito criado por Maria Lugones caracteriza gênero como uma ficção, que sustenta a colonialidade do poder e a dominação racial e de gênero. As referências que ela faz em seu artigo coloniality of gender são para marcar a interseccionalidade entre o lado invisível/obscuro do sistema colonial de gênero e a colonialidade do poder de Quijano, constituindo assim a colonialidade de gênero. ${ }^{3}$

E, por fim, uma exposição comparativa da história de vida de duas mulheres que exerceram grande influência social, cultural e econômica, levando-se em consideração as questões de gênero e da criminologia.

Mulheres, estas, que foram paradigmas, cada uma em sua época específica. São elas Ana Jacinta de São José, a Dona Beja, nos idos de 1830 e Maria das Graças Meneguel, a Xuxa, nos idos de 1990. Essa análise será do ponto da criminologia, do poder econômico exercido pelas duas mulheres e também da submissão desta ao mesmo.

\section{A Mulher e a Criminologia}

As mulheres, ao longo do tempo, têm sido vítimas de conceitos sociais que as coloca numa posição de fragilidade, características responsáveis por uma construção de um estereótipo

DIAS, Letícia Otero. O Feminismo Decolonial de María Lugones. http://eventos.ufgd.edu.br/enepex/anais/arquivos/318.pdf. Acesso em 19/04/2017, às 21:57. 
de pessoas menos capazes. Em matéria criminal, as mulheres também eram consideradas, dóceis, frágeis, muito menos capazes de cometer crimes que os homens e, quando os cometia, seria sempre sob a influência de um homem ou por motivos de paixão, surgindo assim às questões de paradigma de gênero e de dominação masculina.

Sobre a questão Alessandro Baratta, no livro Criminologia e Feminismo, explicita que:

\begin{abstract}
Desta maneira, o paradigma da ciência moderna assegura, assim, a diferença de gênero ignorada. Ainda segundo Harding, a separação entre produção cientifica e a sua aplicação tecnológica na sociedade, separação esta imposta pelo cânone epistemológico androcêntrico, presta-se a reprodução da dominação masculina, bem como da realidade social que a condiciona. Entretanto, esta separação, por seu turno, reflete aquela entre pensamento abstrato (atribuído ao homem) e sentimento dirigido a situações concretas (atribuídos a mulher). Assim, a ciência 'normal' não apenas assegura o poder aos homens, mas também os libera da carga da responsabilidade pública pelas suas consequências tecnológicas, e confina, em boa parte, na esfera privada, a esfera pessoal da atenção e do cuidado reservadas às mulheres.

O denominador comum mínimo para todas as direções que, até o presente momento, seguiu a epistemologia crítica feminista, ou seja, a demolição do modelo antrocêntrico da ciência e a reconstrução de um alternativo, é, portanto, por um lado, a descoberta do simbolismo do gênero que, naquele modelo, vem ocultado, e, por outro lado, a introdução do ponto de vista da luta emancipatória das mulheres do novo modelo. Entretanto, este denominador mínimo, pressupõe, pela teoria de Harding, que não se perca jamais a distinção entre sexo (biológico) gênero (social). ${ }^{4}$
\end{abstract}

No início do estudo da mulher criminosa, a beleza e a capacidade de sedução eram constantemente evocadas para justificar a periculosidade e a capacidade de cometer determinados delitos. Ou seja, no caso das mulheres, dependendo do crime, associava se a beleza ao perigo, uma vez que as mulheres mais atraentes teriam maior capacidade de ludibriar e enganar pessoas. A associação de beleza, sedução e crime foi muito estudada por Lombroso. ${ }^{5}$

Hoje em dia, não se associa a beleza da mulher à prática de crimes, qualquer mulher pode ser autora ou vítima de um crime. Todavia, pode-se dizer que algumas mulheres ainda utilizam da sua sexualidade e sedução para obtenção de vantagens econômicas. E, em muitos casos, essas mulheres passam a ser objetos da sua própria sexualização e se auto exploram para alcançar os benefícios em vários campos sociais.

Pode-se dizer que a situação da mulher nos dias de hoje deve ser analisada focando nas questões da filosofia do gênero, do poder, da imagem e da coisificação.

\footnotetext{
4 BARATTA, Alessandro; STRECK, Lênio Luiz; ANDRADE, Vera Regina Pereira de. Criminologia e Feminismo. Organizado por Carmen Hein de Campos. Porto Alegre, Sulina, 1999, pág 20-21.

${ }^{5}$ LOMBROSO, César.; FERRERO, William. The Female Offender. Colorado, FredB. Rothman \& Co, 1980.
} 


\section{O Poder, a Mulher e a Coisificação}

As relações de poder nas sociedades não são similares. Nas sociedades ocidentais ocorreu a evolução de uma relação de imposição, em sentido genérico, do homem sobre a mulher, denominada por Anibal Quijano de colonialidade de gênero.

María Lugones acrescentou ao conceito de colonialidade de gênero às formas de colonialidade, do ser, do poder e do saber, complementando a ideia de Anibal Quijano em alguns pontos e reescrevendo outros. Um dos pensamentos principais dela é o conceito de sistema colonial/moderno de gênero, e também a intersecção das categorias raça, gênero e colonialidade.

Já com relação ao poder econômico para se chegar a análise do reflexo da situação da mulher na pós-modernidade, pode-se argumentar que o pensamento decolonial se caracteriza por uma série de problematizações em formas de compreender a modernidade, desde perspectivas históricas, sociológicas, culturais e filosóficas. Conforme apresentado na teoria da colonialidade defendida por Anibal Quijano e decolonialidade defendida por Walter Mignolo, demonstrado a posição ocupada pela mulher e as situações de distinção de gênero.

Há de se verificar que muitas das conquistas das mulheres, quebrando paradigmas preconcebidos em verdade, não confirmam em si avanço ou empoderamento, mas um novo alinhamento há colonialidade preestabelecida pelo poder econômico.

Nesta mesma linha há de ser observar efetivamente a utilização da sexualidade da mulher. Atualmente prevalece uma hipocrisia social, quando se fala deste tema. A sociedade tolera a utilização da sexualidade da mulher em alguns casos. Por outro lado, há uma tênue linha entre a sexualidade e a obscenidade. Esta linha caminha de acordo com os interesses sociais da época e suas benesses econômicas.

Nesse aspecto, esta criminalização é mais complexa. Assim, percebemos em muitas sociedades não se criminaliza ou se legaliza a obscenidade, deixando-a em uma área obscura, com a finalidade de amoldar-se à necessidade do momento, o que gera, em última análise, ganhos econômicos para setores específicos e propicia a coisificação da mulher, ou seja, a utilização da mulher e de sua sexualidade como produto.

Por mais que percebamos e condenemos o uso da sexualidade feminina pelo poder econômico, devemos mais uma vez observar nesta tênue linha divisória quem usou e quem se permitiu ser usado.

O poder, a fama e o dinheiro são viciantes. Segundo pode ser percebido para algumas mulheres abdicar de receber dinheiro é tolerável, mas abdicar do poder e da fama seria a própria 
sentença de morte. Assim, essas mulheres preferem usar de sua sexualidade para manutenção dessas vaidades, chegando a admitir a sua própria coisificação.

A expressão "coisificação" deixa clara a realidade a que se refere, significa se transformar em coisa, em objeto, transformar o ius em res, ou seja, redução do ser humano a valores meramente materialistas. A coisificação aqui se refere à mulher, e situações em que é tratada como objeto pelo sexo oposto e por si mesma, virando algo decorativo, instrumento das vontades masculinas, tornando-se marca inanimada, ou seja, coisa.

Conveniente salientar os dizeres de Michael Gross no livro Modelo - O mundo feio das mulheres lindas, que explicita a coisificação da mulher, quando trata das questões de supermodelos:

As supermodelos dos anos 90 são ícones, emblemas de uma sociedade industrial que cada vez mais se aperfeiçoa na arte de produzir réplicas e vender imagens. Embora existam em um meio aparentemente superficial, os modelos são metáforas de temas de importância cultural, como o comércio, a sexualidade, a estética. Através do trabalho dos mercadores de imagens, que as manipulam em fotos e anúncios (e às vezes até na vida real), elas vendem não apenas roupas e cosméticos, mas também uma psicologia complexa e em contínua evolução, assim como uma ambientação social, uma poderosa ficção publicitária que recebeu o nome de 'estilo de vida'. ${ }^{6}$

Cumpre destacar, ainda, as palavras de Cristiane Žovin a cerca do tema:

A apologia ao corpo perfeito é uma das mais cruéis fontes de frustação feminina nos últimos tempos", além da ironia presente nessa busca incessante, pois, simultaneamente ao discurso feminista que prega ganhar mais espaço na sociedade, as mulheres tornam-se cada vez mais magras, menores, esqueléticas e apáticas. $\mathrm{O}$ cárcere emocional da ditadura da beleza impossibilita que o ser humano volte ao seu interior tornando-o opaco e miserável.

No conceito de produto, incluímos também as modelos, aqui denominadas "commodities humanas", especialmente, as dotadas de fama, objeto deste estudo, pois são estas que inserem nos indivíduos os padrões de moda vigentes, contribuindo para a existência da sensação de pertencimento dos mesmos na sociedade, quer dizer, a celebridade-produto é quem tece as relações sociais, esgarçadas por se valerem exatamente de "situação de vinculação dos mitos midiáticos. ${ }^{7}$

\footnotetext{
${ }^{6}$ ŽOVIN. Cristiane. Celebridades: a influência nos padrões de consumo no Brasil. E-papers. Rio de Janeiro, 2010, pág. 20, Citando Michael Gross, No livro Modelo - O mundo feio das mulheres lindas, (Objetiva, 1996), pág. 19. Em https://books.google.com.br/books?id=XhN7BOcXn8C\&pg=PA20\&lpg=PA20\&dq=artista + usando+sexualidade++para + alcançar $+a+$ fama\&source $=b 1 \& o t s=j m d X 9 H$ G1YX\&sig=tF5iL1M4KKFfcyOVaC60XcMTchM\&hl=pt-

BR\&sa $=X \& v e d=0 a h U K E w j S w L u M q Y H U A h U D j Z A K H R x n D 7 U Q 6 A E I R z A H \# v=$ onepage $\& q=$ artista usando sexualidade para alcançar a fama\&f=false. Acesso em 15.06.17.

${ }^{7}$ ŽOVIN. Cristiane. Celebridades: a influência nos padrões de consumo no Brasil. E-papers. Rio de Janeiro, 2010, pág. $\quad 76 . \quad$ Em $\quad$ https://books.google.com.br/books?id=XhN7BOcXn8C\&pg=PA20\&lpg=PA20\&dq=artista + usando+sexualidade++para + alcançar $+a+f a m a \& s o u r c e=b l \& o t s=j m d X 9 H$ G1YX\&sig=tF5iL1M4KKFfcyOVaC60XcMTchM\&hl=ptBR\&sa=X\&ved=0ahUKEwjSwLuMqYHUAhUDjZA KHRxnD7UQ6AEIRzAH\#v=onepage\& $\mathrm{q}=$ artista usando sexualidade para alcançar a fama\&f=false. Acesso em 15.06.17.
} 
Esta coisificação e a ânsia de obter fama e poder, "por seus cinco minutos de mídia" tem-nos apresentado uma série de eventos (Big Brother ${ }^{8}$, A Fazenda ${ }^{9}$, Casa dos $\operatorname{Artistas}^{10}$ ) que confirmam o presente estudo, como pode ser percebido no recorte do jornal abaixo:

"Entenda por que certas pessoas chamam tanta atenção mesmo sem ter nenhum dote artístico. Elas estão na mídia, comparecem aos grandes eventos do show business, aparecem em comerciais de TV, são referência de moda e estilo para um bocado de gente e... Não têm nenhum talento em especial. Não sabem cantar, dançar, atuar, dirigir, não apresentam programas de televisão bem-sucedidos. E, mesmo assim, chamam atenção. Entenda por que essas celebridades são famosas mesmo sem nunca terem se provado donas de grandes dotes artísticos. ${ }^{11}$

Assim, através da atuação da mídia e da audiência, temos uma falsa ideia de empoderamento da mulher, quando em verdade podemos perceber a utilização da imagem sexualizada com a finalidade de se garantir o Poder Econômico em determinada classe ou meio social.

\subsection{A Dominação da Mulher no Período Colonial}

\subsubsection{Ana Jacinta de São José - Dona Beja}

No período Colonial, o Brasil era dominado por um sistema patriarcal que deixava às mulheres pouca margem de ação explícita. Elas eram submissas às vontades dos homens e dominadas pelo pai e, posteriormente, pelos maridos. Quebrando esse paradigma da submissão e utilizando a sexualidade para dominar o poder econômico de uma região, tem-se o surgimento da Dona Beja, no Período Colonial, na Vila de São Domingos do Araxá.

Em 1805, estabeleceu-se em São Domingos do Araxá, Ana Jacinta de São José, uma moça de grandiosa beleza, a qual despertava a atenção e interesse dos homens e a inveja e ira

\footnotetext{
${ }^{8}$ Big Brother é um popular Reality Show onde, durante cerca de três meses, um grupo de pessoas (geralmente menos de 15) ficam confinados sem contato com o mundo exterior. Wikipédia. Em https://pt.wikipedia.org/wiki/Big_Brother_(reality_show). Acesso em 17.06.17.

${ }^{9}$ A Fazenda é um reality show brasileiro produzido e exibido pela RecordTV. É baseado no formato The Farm, que foi criado em 2001 pela produtora sueca Strix e já foi apresentado com sucesso em mais de 40 países. Wikipédia. Em https://pt.wikipedia.org/wiki/A_Fazenda. Acesso em 17.06.17.

${ }^{10}$ Casa dos Artistas foi uma série de reality show brasileira exibida pelo SBT entre 2001 e 2004, composto por um grupo de famosos disputando o prêmio principal. O final da primeira temporada, exibido em 16 de dezembro de 2001, rendeu a maior audiência da história do SBT, com média de 47 pontos e picos de 55, contra 18 pontos da segunda colocada.

${ }^{11}$ Tá fácil... Celebridades que conseguiram fama mesmo sem ter nenhum talento. Publicada em: 27/01/2015 08h05. Em http://revistamonet.globo.com/Listas/noticia/2015/01/ta-facil-celebridades-que-conseguiram-famamesmo-sem-ter-nenhum-talento.html. Acessp em 15.06.17.
} 
das mulheres. Ana Jacinta tornou-se noiva de Manoel Fernando Sampaio e foi apelidada por ele como Beja, em comparação à beleza da flor "beijo".

Beja foi raptada, antes de seu casamento, pelo Ouvidor do Rei, Dr. Joaquim Inácio Silveira da Motta, que ficou fascinado com sua beleza. Por dois anos, Beja viveu como amante do Ouvidor na Vila do Paracatu do Príncipe.

Passado esse tempo, Beja retornou a São Domingos do Araxá e encontrou um ambiente hostil. A sociedade local era extremamente conservadora e não via Beja como vítima, mas como uma mulher sedutora de comportamento duvidoso, perigoso e uma ameaça aos homens.

Para vencer as adversidades, Beja tornou-se outra pessoa, rica e poderosa, exercendo o fascínio sobre todos os homens, transformou-se na maior personalidade da região. Inclusive, continuou a exercer seu fascínio sobre seu antigo noivo, Manoel Fernando Sampaio, e com ele teve uma filha, e manteve uma relação bastante próxima e duradoura, em que pese o mesmo já estar casado com outra mulher.

Sobre Beja, Lourdes Zema ${ }^{12}$ afirma que:

Seu poder e sua beleza foram associados às virtudes afrodisíacas das águas de Araxá. Nada pode ser negado à veracidade da história e à correlação de Beja-Araxá, porque ela ressurgiu no novo século como emblema da cidade, associada às águas locais, atraindo turistas à região. ${ }^{13}$

Dona Beja possuía uma chácara, fora da cidade onde passava a maior parte do tempo e neste local recebia os seus admiradores. A Vila de São Domingos do Araxá passa a ser visitada por pessoas influentes da região.

Com relação ao Poder Econômico exercido por Beja, através do uso de sua sexualidade, Lourdes Zema dispõe que:

Essa casa possuía vastos salões para festas e recepções, era em estilo colonial, cercada de árvores...Era imensa a legião de admiradores vindos das cidades próximas, até de cidades de São Paulo, e nesta casa, ela recebia os homens para festas em troca de presentes. D. Beja impõe regras e se coloca em posição superior: é ela quem define a relação com os homens, é ela quem escolhe seus parceiros sexuais. ${ }^{14}$

12 Lourdes Zema, historiadora e artista plástica da cidade de Araxá. http://www.descubraminas.com.br/Turismo/DestinoPagina.aspx?cod_destino=41\&cod_pgi=2487 <acesso em $15 / 03 / 2017$, as 15:30>

13 ANA JACINTA DE SÃO JOSÉ - $\quad$ D. $\quad$ BEJA. http://www.descubraminas.com.br/Turismo/DestinoPagina.aspx?cod_destino=41\&cod_pgi=2487. Acesso em 17.06.17.

14 ANA JACINTA DE SÃO JOSÉ - D. $\quad$ BEJA. Em http://www.descubraminas.com.br/Turismo/DestinoPagina.aspx?cod_destino=41\&cod_pgi=2487. Acesso em 17.06.17. 
Após os 35 anos, Beja se retira da vida pública para se dedicar às filhas. Escolhe para viver a localidade de Bagagem, hoje, Estrela do Sul, onde estava acontecendo uma corrida pelos diamantes. Beja, então, se dedica à atividade do garimpo, como uma das principais figuras que se destacaram neste ramo na região. A mulher sedutora passa a viver uma vida recatada, voltada à religião e à caridade. Foi a aceita pela comunidade de Bagagem e participou da vida diária da cidade. $^{15}$

Diante do narrado, constata-se que Dona Beja, mesmo num período colonial, destacouse por utilizar da sua sexualidade para subjugar o Poder econômico, conseguindo vantagens e destacar-se, quebrando os paradigmas da época de submissão de gênero.

\subsection{A Dominação sobre a Mulher no Período Deocolonial}

\subsubsection{Maria das Graças Meneguel - Xuxa ${ }^{16}$}

Maria das Graça "Xuxa" Meneghel, começou sua carreira como modelo, atriz e animadora de festas. Galgou notoriedade em 1980, quando começou a namorar Peléc ${ }^{17}$. Xuxa prosseguiu sua carreira como atriz de um filme que, à época era polêmico e, que hoje seria classificado como apológico à pedofilia, de nome "Amor Estranho Amor"18. Estampou a capa da revista masculina Playboy em 1982. ${ }^{19}$

Em 1983, animava o "Baile do Galo"20", de um time de futebol tradicional da cidade de Belo Horizonte, dançando com sua bandeira sobre a taça do Galo ${ }^{21}$, e iniciou uma carreira na televisão como apresentadora de programas infantis. Nos anos noventa, iniciou, midiaticamente, um romance com Ayrton Senna, piloto de Fórmula 1, ídolo e, então, não apenas

$15 \quad$ ANA JACINTA DE SÃO JOSÉ - $\quad$ D.
http://www.descubraminas.com.br/Turismo/DestinoPagina.aspx?cod_destino=41\&cod_pgi=2487. Acesso em 17.06.17.

${ }^{16}$ Registre-se que trata de uma mera análise acadêmica, utilizando a referida apenas como paradigma teórico da tese proposta no estudo, não necessariamente, imputando à referida qualquer conduta ou procedimento.

17 Os Namorados da Xuxa. Em http://famosos.culturamix.com/noticias/os-namorados-da-xuxa. Acesso: 20.05.2017.

18 Filme Amor Estranho Amor ( 1982 COMPLETO VHS ) qualidade baixa. Em https://www.youtube.com/watch?v=jHuMcwZNPwY. Acesso: 20.05.2017.

19 Playboy - Capa: Xuxa, As Fotos Que Pelé Quase Proibiu! - Edição Dezembro 1982. Em http://garotadaplayboy.blogspot.com.br/2012/02/playboy-xuxa-as-fotos-que-pele quase.html?zx=8234b0460ec352f3. Acesso: 20.05.2017.

${ }^{20}$ Clube Atlético Mineiro. Em http://www.atletico.com.br/. Acesso: 20.05.2017.

${ }^{21}$ Xuxa dança na Taça do Galo! (carnaval em 1983). Em https://www.youtube.com/watch?v=Aqfhc69fIvI. Acesso: 20.05.2017. 
do Brasil como do mundo. "Xuxa construiu o maior império de entretenimento infantil iberoamericano, presente em todo Brasil, países da América Latina, Estados Unidos e Europa. "22

Há de se mirar o olhar no sentido que, à medida que ela ascendia ao sucesso como apresentadora infantil seu passado foi sendo propositalmente omitido, seja por ela, seja pelos veículos de mídia aos quais se vinculou, em que pese que vários de seus programas sempre tinham mulheres sexualizadas. Como pode ser comprovado através da presença da sua equipe de "Paquitas" - meninas que disputavam vorazmente a oportunidade de terem sua presença no palco e das coreografias das danças. "As Paquitas" eram pressionadas para terem corpos e peles perfeitas" ${ }^{23}$, mesmo que fosse para o público infanto-juvenil.

Certo é que sejam os conceitos morais, sociais, relações de gênero ou qualquer que seja, foram desprezados com o intuito único da obtenção de ganhos econômicos, apenas para ascender ao poder econômico.

Percebe-se que por mais avassalador que fosse o sucesso, a imagem criada ao redor da personagem Xuxa, esta continuou submissa à colonialidade da mulher bela, sexualizada e procriadora. Pois então, a rainha dos baixinhos foi apenas uma representação criada pela mídia, detentora e manipuladora do Poder Econômico. Xuxa e a sua imagem foram utilizadas e se permitiram o ser, como produto lucrativo, ou seja, comprovando a teoria da coisificação da mulher pelo poder econômico.

\section{Conclusão}

Esta pesquisa frente à parte bibliográfica foi concluída com a confirmação de que a mulher ainda é tratada, em muitos casos, como submissa e inferior, mesmo com leis protegendo-a contra a violência moral, psicológica, física e simbólica. Verificou-se, também, que as desigualdades possuem origens sociais, culturais, políticas e econômicas, que vêm se perpetuando, mesmo que disfarçadamente, ao correr dos anos.

Nos casos apresentados, verificamos que o paradigma da mulher "coisa", propriedade do pai e depois adquirida pelo marido, não modificou muito no decorrer dos tempos. Existiu uma mudança de perspectiva, antes à mulher era imposta a sua condição de objeto, de coisa. Hoje a mulher continua ainda sendo vista como um objeto, mas, na maioria das vezes, a sua

\footnotetext{
${ }^{22}$ Xuxa. Em https://pt.wikipedia.org/wiki/Xuxa. Acesso: 20.05.2017.

23 Aos 39, ex-paquita Miuxa lembra pressão por beleza e mágoa com Xuxa. http://www.capitalteresina.com.br/noticias/entretenimento/aos-39-ex-paquita-miuxa-lembra-pressao-por-belezae-magoa-com-xuxa-32056.html. Acesso: 20.05.2017.
} 
coisificação também acontece por vontade própria, com o objetivo de alcançar a fama e prestígio social, através do Poder Econômico que sua imagem pode vir a propiciar.

No início do estudo da mulher pela criminologia, a beleza e a capacidade de sedução eram constantemente evocadas para justificar a periculosidade e a capacidade de cometer determinados delitos. Nesse aspecto, hoje esta criminalização é mais complexa. Em muitas sociedades não se criminaliza ou se legaliza a obscenidade, a sexualização, devido ao ganho econômico para setores específicos, o que propicia a coisificação da mulher, ou seja, a utilização da mulher e de sua sexualidade como produto, para obtenção de lucro e ganhos econômicos.

Ao analisarmos a história das mulheres escolhidas como paradigmas, verificamos a coisificação da mulher e a sexualização delas pelo Poder Econômico exercido, todavia, de formas distintas.

Constata-se que a Dona Beja quebrou esse paradigma social, pai/marido, tornou-se "objeto" por força das circunstâncias, e soube administrar a sua coisificação, pois discernia sobre sua sexualidade e o sexo. E, ao que nos parece, conseguiu se libertar da sua própria coisificação.

Em contrapartida, Xuxa por mais independência econômica que tenha, continuou sendo propriedade da coisificação de sua pessoa e imagem, dependente da atual sociedade midiática, enquanto pessoa e profissional.

Percebemos que hoje as "Xuxas" 24 personificadas em diversas mulheres que no afã do sucesso profissional econômico se reduzem à objeto sexual. E, de forma mais lamentável usando o sexo, a sexualidade e o gênero para galgar poder social, midiático e econômico, tentando mostras sua independência, ao passo que somente fazem provar a sua submissão ao Poder Econômico.

Desta forma, os resultados dessa análise indicam que mesmo a nova visão colonialista e a decolonialista da sociedade, da economia e do gênero; não possuem o condão de modificar a submissão que foi creditada às mulheres. E, mais, que em alguns casos, a mulher consegue realmente exercer o poder econômico com supremacia, mas na maioria dos casos ela é coisificada pela sociedade, pela cultura e, principalmente, pelo poder econômico ao qual está submetida.

\footnotetext{
${ }^{24} \mathrm{O}$ termo aqui utilizado refere-se à generalidade de pessoas que tiveram sua individualidade sucumbida pela publicidade e coisificação, não se referindo especificamente à pessoa Maria das Graças Meneguel ou a sua personificação artística.
} 
Em sentido oposto à percepção geral, acerca da atual independência e empoderamento das mulheres, nos parece que muitas vezes que este poder adquirido nada mais é que reflexo do uso da própria mulher pelo poder econômico, da sua coisificação. Não raras vezes exploradas em sua sexualidade, quando sua efetiva aparência é de dominação frente a submissão ao poder econômico.

Atualmente, está posto, de forma muito cristalina que várias pessoas estão a usar o gênero como forma de obter, nas palavras de Andy Warhol, seus quinze minutos de fama, consequência da atual sociedade de aparências.

\section{BIBLIOGRAFIA}

ANA JACINTA DE SÃO JOSÉ- D. BEJA. Em
http://www.descubraminas.com.br/Turismo/DestinoPagina.aspx?cod_destino=41\&cod_pgi=2 487. Acesso em 17.06.17.

ARAÚJO, Emanuel. “A Arte da Sedução: Sexualidade Feminina na Colônia. In: Priore, Mary Del. (org) Historia das Mulheres no Brasil. São Paulo, Contexto, 2007.

BARATTA, Alessandro; STRECK, Lênio Luiz; ANDRADE, Vera Regina Pereira de. Criminologia e Feminismo. Organizado por Carmen Hein de Campos. Porto Alegre, Sulina, 1999.

DIAS, Letícia Otero. O Feminismo Decolonial de María Lugones. http://eventos.ufgd.edu.br/enepex/anais/arquivos/318.pdf. Acesso em 19/04/2017.

Filme Amor Estranho Amor ( 1982 COMPLETO VHS ) qualidade baixa. Em https://www.youtube.com/watch?v=jHuMcwZNPwY. Acesso: 20.05.2017.

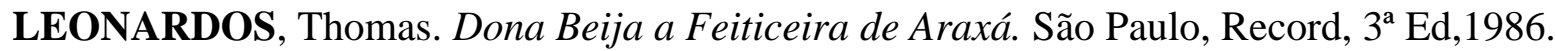

LOMBROSO, César.; FERRERO, William. The Female Offender. Colorado, FredB. Rothman \& Co, 1980 .

LOURDES ZEMA, historiadora e artista plástica da cidade de Araxá. http://www.descubraminas.com.br/Turismo/DestinoPagina.aspx?cod_destino=41\&cod_pgi=2 487. Acesso em 17.06.17. 
LUGONES, María. “Subjetividad esclava, colonialidad de género, marginalidad y opresiones múltiples”. Pensando los feminismos en Bolivia: SerieForos 2. $1^{\mathrm{a}}$ ed. La Paz, Conexión Fondo de Emancipación, 2012.

MIGNOLO, Walter D. La idea de américa latina: la herida colonial y la opción decolonial. Barcelona: Gedisa, 2005.

MIGNOLO, Walter D. Novas reflexões sobre "Ideia da América Latina”: a direita, a esquerda e a opção descolonial. Caderno CRH, v.21, n.53, 2008.

OS NAMORADOS DA XUXA. Em http://famosos.culturamix.com/noticias/os-namoradosda-xuxa. Acesso: 20.05.2017.

\section{PLAYBOY - Capa: Xuxa, As Fotos Que Pelé Quase Proibiu! - Edição Dezembro 1982.} Em http://garotadaplayboy.blogspot.com.br/2012/02/playboy-xuxa-as-fotos-que-pele quase.html?zx=8234b0460ec352f3. Acesso: 20.05.2017.

QUIJANO, Aníbal. “Capítulo de Aníbal Quijano. Colonialidad del poder, eurocentrismo y América Latina”. La colonialidad del saber: eurocentrismo y ciências sociales. Perspectivas Latinoamericanas. Buenos Aires, CLACSO, 2000.

Tá fácil... Celebridades que conseguiram fama mesmo sem ter nenhum talento. Publicada em: 27/01/2015 - 08h05. Em http://revistamonet.globo.com/Listas/noticia/2015/01/ta-facilcelebridades-que-conseguiram-fama-mesmo-sem-ter-nenhum-talento.html. Acesso em 15.06.17.

Xuxa dança na Taça do Galo! (carnaval em 1983). Em https://www.youtube.com/watch?v=Aqfhc69fIvI. Acesso: 20.05.2017.

Xuxa. Em https://pt.wikipedia.org/wiki/Xuxa. Acesso: 20.05.2017.

ŽOVIN. Cristiane. Celebridades: a influência nos padrões de consumo no Brasil. E-papers. Rio de Janeiro, 2010. Em https://books.google.com.br/books?id=XhN7BOcXn- 
RELACult - Revista Latino-Americana de Estudos em Cultura e Sociedade

Revista Latinoamericana de Estudios en Cultura y Sociedad | Latin American Journal of Studies in Culture and Society V. 03, ed. especial, dez., 2017, artigo no 463 | relacult.claec.org | e-ISSN: 2525-7870

8C\&pg=PA20\&lpg=PA20\&dq=artista+usando+sexualidade++para+alcançar $+\mathrm{a}+$ fama\&sourc e=bl\&ots=jmdX9HG1YX\&sig=tF5iL1M4KKFfcyOVaC60XcMTchM\&hl=pt-

BR\&sa=X\&ved=0ahUKEwjSwLuMqYHUAhUDjZAKHRxnD7UQ6AEIRzAH\#v=onepage

$\& \mathrm{q}=$ artista usando sexualidade para alcançar a fama\&f=false. Acesso em 15.06.17. 